\title{
Assessment of Beef Quality Determinants in the Retailing Premises
}

\author{
Joseph Tenson Mwashiuya1', Samwel Victor Manyele², George Mwaluko \\ ${ }^{1}$ Department of Mechanical and Industrial Engineering, University of Dar es Salaam, Dar es Salaam, Tanzania \\ ${ }^{2}$ Department of Chemical and Mining Engineering, University of Dar es Salaam, Dar es Salaam, Tanzania \\ Email: joseftenson@yahoo.com, smanyele@udsm.ac.tz,mwalukogeorge@yahoo.com
}

How to cite this paper: Mwashiuya, J.T., Manyele, S.V. and Mwaluko, G. (2019) Assessment of Beef Quality Determinants in the Retailing Premises. Engineering, 11, 675-702.

https://doi.org/10.4236/eng.2019.1110044

Received: July 19, 2019

Accepted: October 7, 2019

Published: October 10, 2019

Copyright ( 2019 by author(s) and Scientific Research Publishing Inc. This work is licensed under the Creative Commons Attribution International License (CC BY 4.0).

http://creativecommons.org/licenses/by/4.0/

\section{cc) (i) Open Access}

\begin{abstract}
This study explains how infrastructure and beef processing practices in beef retailing premises (BRPs) are useful for beef purchasing decision. In this respect, features and beef retailing practices were assessed against the questionability of beef that is retailed in least developing countries (LDCs). This assessment was carried out by testing the null hypothesis that hypothesizes that BRPs in Dar es Salaam and Mbeya cities do not comply with the FAO technical requirements. The retailed beef in many BRPs is compromised with the status of the infrastructural development, the situation that may result in the questionability of the consumed beef. The Likert based information regarding 22 beef quality impacting factors (BQIF) from BRPs in Dar es Salaam and Mbeya, respectively, was analyzed with respect to the gaps identified and beef retailing conceptual model. This study is important as it provides general picture in connection to the status of the assessed BQIF in BRPs for the cities in the least developing countries (LDCs). In this regard, the study has shown that the compliance of BRPs in the LDCs' cities is too weak to meet the infrastructural technical requirements due to existence of more stringent provisions in the developed specifications. The study finally identified the local infrastructural beef quality determinants in LDCs' BRPs as the gap to be bridged by other studies.
\end{abstract}

\section{Keywords}

Beef Quality Impacting Factors, Beef Retailing Premises, Beef Processing Area, Hygiene in Beef Processing and Storage, Least Developing Countries

\section{Introduction}

Meat retailing is one of the largest fractions of the agricultural market that significantly differs from other food business in terms of technical requirements in 
processing technology, storage condition and elasticity of demand [1]. The current technology depends on the mass inspection based on grading systems, such as Meat Standards Australia (MSA) of processed beef for ensuring its acceptability [2]. Although this system resulted in general categorization based on quality and tenderness differences, the value of the produced beef is compromised due to imprecision of the sorting methodology [2] [3]. Condition of the storage in beef trading is challenged by cold chain management during beef processing, transportation and retailing, situations that resulted in questionability of produced beef [4] [5] [6]. Elasticity of demand for beef is complex, multifaceted and evolving following the formation of new and important quality cues over time which is connected to attributes such as suitability, consistency in quality, convenience in preparation, price and price of beef relative to price of its substitutes [7]. Therefore, the noted challenges that are quantified by industrialized and developing world's viewpoints have raised the questionability of beef in retailing shops. The former scenario is explained based on the concerns and consequential costs raised in the developed world's community as a result of food safety incidents that caused public attention on the causes, effects and preventions of food hazards [8]. The latter scenario involved infrastructural beef retailing as one of the main beef quality management challenges in post-slaughter animal handling [4] [5] [9] [10].

Various studies have been conducted in the assessment of beef quality determinants in the BRPs. These studies were detailed on the means infrastructure, sanitation and meat handling practices have contributed to the beef purchasing decision [5] [10]. In this respect, it was shown that infrastructural development in LDCs is too weak to question the beef retailed in the cities of these countries [4] [5] [11] [12]. This questionability is described based on possibilities of contamination and bacteriological infection in beef due to non-appropriately handling during beef retailing [9]. It was further documented that, beef undergoes various poorly managed handling processes which have adverse effect on meat quality during retailing [4] [13] [14] [15] [16] [17].

Different from other studies, this study focuses on the infrastructural assessment of unbranded beef retailing with respect to 22 BQIF in Dar es Salaam and Mbeya cities. In connection to this, factors in connection to: infrastructural fixed construction materials, hygienic practices, cold chain management and adherences to the maintenance conditions were comprehensively analyzed [4] [5] [15] [16]. The study is aimed on providing knowledge and skills to the key players involved in food safety specifically on quality aspect of retailed beef in various BRPs. It is specifically presented infrastructural factors that influence the appropriate choice for unbranded beef in the BRPs.

\section{Literature Review}

\subsection{Basic Requirements for Beef Retail Premises}

Food retailing includes both organized modern retail outlets such as supermar- 
kets, hypermarkets and traditional groceries where beef is processed and sold [18] [19] [20] [21]. In these areas food safety issues, risk management options and hygienic practices need to be considered for protection of health of public consumers in connection to beef supply [6] [20] [22]. In this regards, twenty two (22) BQIF from five (5) basic beef processing managerial features in retail beef shops as identified in other studies [18] [19] [20] [22]-[29], as key study parameters as shown in Table 1 , should be addressed.

Entrance to BRPs should be fixed with both pest proof and cleanable self-locking doors that may be designed to open by pushing from all sides to avoid contaminating meat seller's handles [17] [18] [20] [28] [29] They also needed to be fitted with smooth, impervious and easy to clean construction materials on counters, ceilings, floors and walls [17] [28] [29] [30] [31]. The mentioned construction materials should properly be grouted, sealed and internally jointed in the named features of beef retail shops. These features have to be both appropriately

Table 1. Categorization of beef quality impacting parameters based on basic features of in beef retail shops (adopted and customized from other studies).

\begin{tabular}{|c|c|c|}
\hline Basic feature (s) & Variable & Beef quality impacting feature \\
\hline \multirow{4}{*}{ Entrances } & R01 & Glassed doors \\
\hline & R02 & Pest screen in doors \\
\hline & R03 & Door in closed position \\
\hline & R04 & Appropriate maintained \\
\hline \multirow[t]{3}{*}{ Room structural surfaces } & R05 & Appropriate construction material \\
\hline & R06 & Clean room structural surfaces \\
\hline & R07 & Clean beef processing area \\
\hline \multirow[t]{3}{*}{ Beef processing area } & R08 & Appropriate maintained beef processing area \\
\hline & R09 & Appropriate construction materials \\
\hline & R10 & Storage practices (beef only) \\
\hline \multirow[t]{6}{*}{ Beef quality handling } & R11 & Appropriate ventilated beef \\
\hline & R12 & Cold storage (freezers \& refrigerators) \\
\hline & R13 & Butchers with uniform \\
\hline & R14 & Clean uniform \\
\hline & R15 & Certified butchers (food safety) \\
\hline & R16 & Butchers with exchanging room \\
\hline \multirow{6}{*}{ Hygiene condition } & R17 & Valid medical certificate \\
\hline & R18 & Appropriate cutting table \\
\hline & R19 & Stainless steel hanging hook \\
\hline & $\mathrm{R} 20$ & Toilet availability \\
\hline & $\mathrm{R} 21$ & Butcher with cleaning facilities \\
\hline & R22 & Beef displayed at butcher's side \\
\hline
\end{tabular}


maintained and regularly cleaned in order to avoid paint flacking, cracks and damage. Dirty and poorly maintained ceiling, floor and wall in butchers are not considered as first line concerns in food safety as they do not directly contact the meat, instead, they result into aesthetic impact to beef consumers [30] [31].

Beef processing (cutting and weighing) area in a beef retail shop should be appropriately arranged with a clear separation from a hooked beef in a butcher's space, storage facilities, customers' waiting point and hand washing station [6] [17] [19] [26] [29]. This area, which should be also appropriately ventilated, is needed to be constructed with non-dark and cleanable materials like plastics, concretes, wood and any other food grade materials [29]. Beef in the storage facility or butchers' hanging space, should not be mixed with other types of meat and other perishable food [6] [29].

Food safety conditions with respect to hygienic requirements in BRPs should be adhered to. While working in BRPs, staff should wash their hands regularly and maintain high degree of cleanliness by wearing clean uniform and head gear [6]. In addition, adequate toilet and hand washing facilities should be provided in the area where beef is retailed [18] [29]. Furthermore, sellers in BRPs should have approved licenses for the premises where such activities are carried out [19] [32]. The named licensing is normally indicated by various certification schemes that includes sellers' medical examination, certified beef processing units and quality assurance for the protected designation of origin (PDO) [6] [23] [24] [25] [26] [29].

\subsection{Infrastructural Challenges in Beef Selling Premises}

Beef retail shops in many countries are challenged with a failure to comply with food safety requirements due of various reasons like lacking of legal framework, insufficient knowledge in good hygienic practices in meat handling and economic point of view [5] [6] [17] [25] [26] [32] [33]. This noncompliance has been indicated in many developing countries where entrances to some beef retailing shops were fixed with inappropriate doors that were manually operated which allows meat contamination from dusts, pests and harbored pathogens in the door's handles [34] [35].

Ceiling, floor and walls in these non-complied beef retail shops were also fixed with inappropriate construction materials. This condition resulted into dirty and dusty on these features [31] [32] [36] [37]. A study on the microbial quality of raw meat sold in some parts of Ibadan Metropolis, Nigeria, has shown similar noncompliance with respect to absence of ceilings in butcher shops [37]. The studies have shown that walls in butchers of Alexandria were contaminated, a situation which indicated that the wall construction materials were not appropriate for beef retailing premises [37]. Similarly, other studies, indicated non-compliance to wall requirements for beef retailing premises in the surveyed butchers in Kampala, Uganda, following non-adherence to the hygienic and maintenance requirements [24]. In connection to this, nearly a half of butcher shops in Gon- 
dar town Ethiopia, were neither painted in white nor walled with appropriate construction materials, a situations which influences harboring of microbial organisms [31].

Compliance with the specification for beef processing is poor in many BRPs especially in developing countries where beef is processed without adherence to sanitation and hygienic requirements [20] [25] [26] [32]. In connection to this, it was reported that the Tanzanian high quality processed beef was accounted for $5 \%$ of the traded beef within the country [19] [20]. It was further reported that $34 \%$ of this premium beef is imported from other countries, the situation that elaborates the gap that has to be bridged in meat sector [20]. Other study has shown that beef was retailed in the premises that are lacking basic hygiene requirements in Al-Mafraq governorate, Jordan [25].

Prevalence of Salmonella and Shigella in meat processing facilities indicated a non-conformance to the meat retailing in the surveyed butchers in Gondar town, Ethiopia, and Al-Mafraq, Jordan and Nepal [25] [26] [31]. On the other hand, other studies have shown that beef processing accessories in the surveyed butchers in Nairobi and Isiolo counties were not adequately cleaned, the factor that influences microbial contamination [5]. Similarly, the assessment of beef microbial contamination at abattoir and meat retailing in Morogoro municipality, Tanzania, indicated non-compliance to the meat processing as bony meat was observed to be cut with hand axe on a piece of wood locally known as "kigogo" [10].

Beef storage in dirty and non-maintained storage facilities is common in many developing countries as it was shown in the surveyed butchers in Gondar town, Ethiopia, and Butwal Municipality in Nepal [25] [31]. In this respect, beef was none-hygienically stored with meat from other species, fish, evisceration products and other meat retailing leftover [25]. This storage practice together with the habit of using unclean storage facilities with inappropriate temperature controlling capacity have resulted into microbial growth [25] [31]. Poor storage of beef was also observed in Kampala, Uganda during which not only $11.4 \%$ of the surveyed BRPs were operated in poor environment, but $47.9 \%$ of had inappropriate storage facilities. In addition to that, an assessment study in Kenyan counties revealed this nonconformance as the butcher operators stocking the only daily sale meat capacity that hanged in open spaces in the butchers and exposed to environmental contamination from dusts and flies [5]. Inappropriately meat cutting was also observed in the surveyed retailing shops in Kampala, Uganda Nairobi and Isiolo counties, Kenya, Morogoro municipality, Tanzania [5] [31]. Most of butchers in these cities had wood cutting surfaces in which residues of meat are stuck, the situation that compromises with effective cleaning.

Adherence to the good hygienic practices during beef retailing was not the case in many states, the case that resulted into a broad range of adverse health effects including increasing the risk of susceptibility to food borne disease [25] [31] [32]. In Gondar town, Ethiopia and Kampala, Uganda, most of staff sur- 
veyed wore personal clothes during beef retailing [31] [32]. Studies in Morogoro municipality, on the other hand, reported different situation in which although the staff in all of the surveyed butchers in Morogoro municipality were fitted in protective clothing, $62.5 \%$ of them were in dirty uniforms. Salmonella isolates identified from meat samples, swabs from hand and knife together with chopping board surfaces in Gondar town, Ethiopia is interpreted as the fact for non-compliance to this requirement [10] [23]. Another study has shown that the increasing tendency by meat sellers in Al-Mafraq governorate to slaughter their animal inside the butchers shops [25].

The legal frame-work in many developing countries is too fragmented for their respective BRPs to be appropriately monitored [20] [22] [25] [26]. For, example, although $72.6 \%$ of respondents in the surveyed butchers in Kampala, Uganda mentioned that they were medically examined, none of them mentioned or showed the medical examination certificate [32]. Similarly, the study on the sanitation and hygiene meat handling in Nairobi and Isiolo counties in Kenya indicated that $94 \%$ and $88 \%$, respectively, did not have medical certificates [5].

Implementation of the international recognized certification, often through the International Organization for Standardization (ISO) is recommended for smoothly trading of beef and beef products [24] [25]. However, studies have shown the means in which states, especially the developing ones were failed to implement the quality assurance certification schemes in beef trading especially in the developing states [6] [24] [27]. For example, it was reported that lacking of collective actions between producers and retailers as well as dispersity of the producers were noted as the main limiting factors for establishment of the origin-based certification system [24].

\section{Methodology}

\subsection{Beef Retailing Conceptual Model}

Factors influencing the quality of beef in the selling premises were established from the actual observation and literature review technical requirements based on the conceptualized beef retailing model shown in Figure 1. This model was designed based on information on beef quality technical requirements and the gap observed in actual situation. The conceptual model expresses the beef retailing specifically on the impact of both infrastructural features and the respective processes to the beef quality. This model was developed from a total of twenty two (22) main components, starting from the time beef enters a retail shop to the moment beef is taken by consumers. The conceptual framework was constructed using three main blocks, that is, the building and its design features, butchers internal feature, and health and sanitation practices.

\subsection{Beef Retailing Assessment Checklist}

The beef retailing assessment checklist was designed based on the described conceptual model. The model includes features that are further detailed to beef 


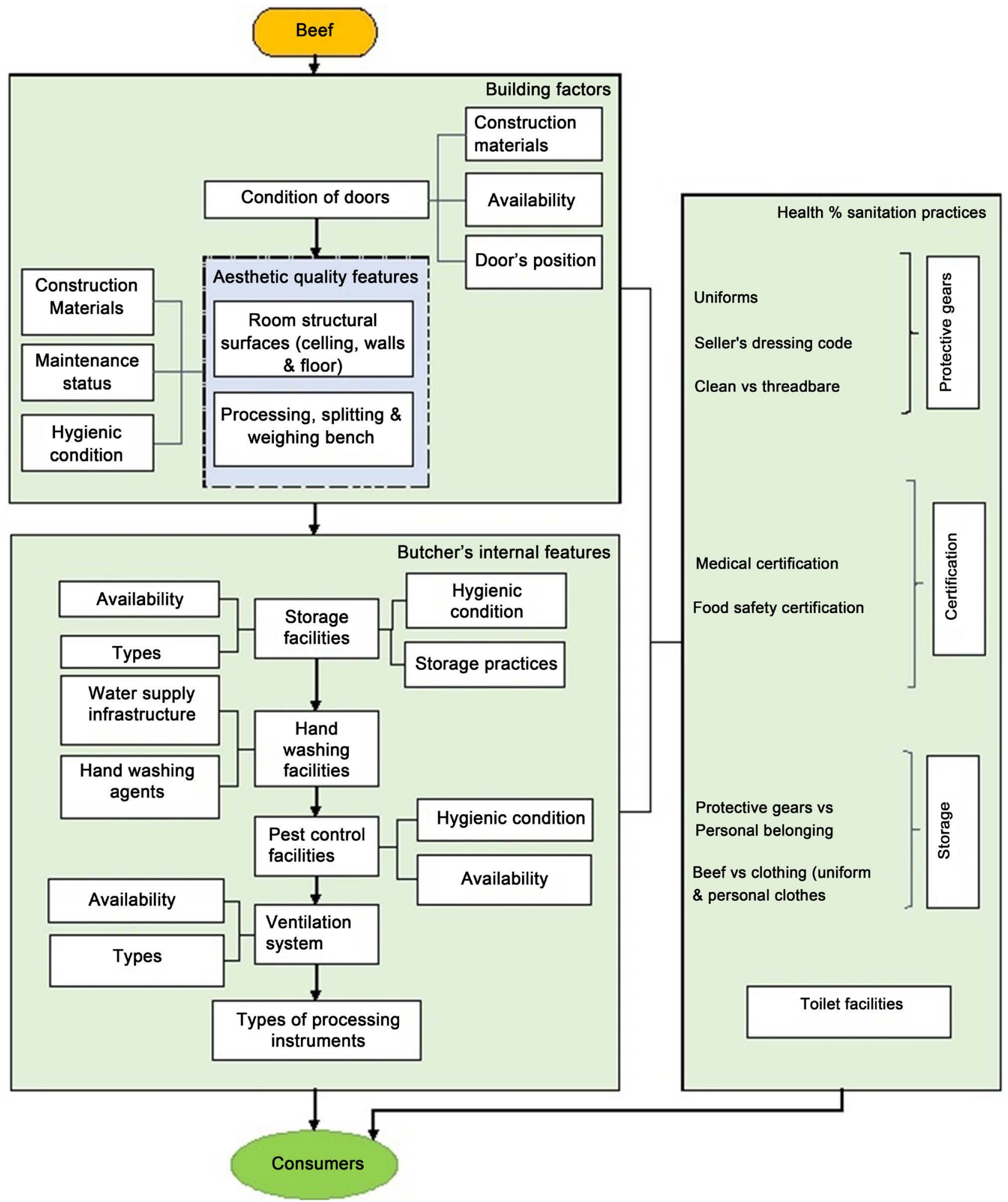

Figure 1. Conceptualized model that indicates beef quality impacting factors in beef retailing shops.

quality impacting factors in a pre-description mode within the selling premises. This resulted into a checklist with a total of twenty four (24) of which twenty two (22) are positively and negatively worded items, i.e., Likert items. 


\subsection{Data Collection and Sample Size}

The study on compliance of butchers or selling points based on design features was conducted using a sample size of 95 and 29 butchers in Dar es Salaam and Mbeya cities, respectively. Since the butchers in two cities are located in different wards, the number of butchers surveyed per ward is summarized in Figure 2, which shows butchers, wards and district covered during this study. The large number of butchers in Kinondoni district can be attributed to the fact that the timing of data collection went in parallel with regulatory activities by Tanzania Food and Drugs Authority (TFDA), hence leading to more butchers being included in the survey.

\subsection{Determination of Total and Overall Scores}

Based on this information, together with the specifications, the BQIF from the identified Likert items were analyzed. The total compliance indices were constructed by comparing the infrastructural requirements for beef quality management against data gathered along the beef retailing. Each of the listed requirements was given a unique number, $\underline{R}_{i}(\mathrm{i}=1,2, \ldots, 22)$ indicating requirement number one, two, and so on as shown in Table 1. As in the past studies, on compliance to the requirement [38], this study adopts an ascending scoring system at $0,0.25,0.50$, and 1 compliance levels. The parameters that should be addressed on handling of beef quality management along the chain were assessed against 22 requirements developed based on the criteria. The criterion set used, provides the decision rule to which the computed compliance index leads to acceptance or rejection of the hypotheses developed in this study. All the entities with compliance indices less than $20 \%$ were excluded from the population sampled.

\subsection{Overall Analysis for Beef Retailing Premises}

The gathered information was analyzed and interpreted by using spread sheet of Microsoft Excel 2010 based on two main hypotheses, namely: the beef retailing

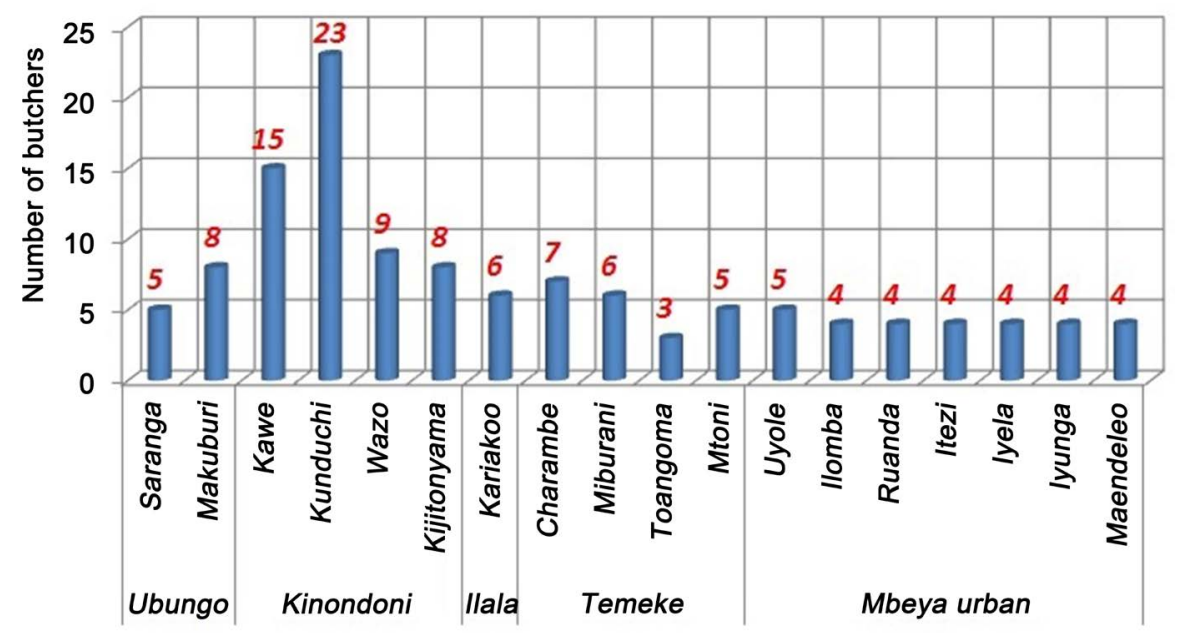

Figure 2. Distribution of the butchers surveyed by wards and districts. 
shops in Tanzanian cities do not comply with food quality technical requirements; and the level of compliance of beef retailing shops with respect retailing infrastructure in different cities is significantly different. The Likert scale data were re-arranged and organized to provide: overall and average scores of all of the assessed features in each of the assessed beef retailing premises (BRPs); and total score of each of the assessed feature across all BRPs before being presented in graphics, tables and flow charts. In this respect, the overall score $(O S)$ for each butcher with respect to the assessed BQIF, was determined from the total number of the assessed BQIF, $N_{d f}$ (where, $N_{d f}=22$ ) and the given count of frequency for each beef quality criterion assessed, $S_{c}$ as shown in Equation (1):

$$
O S(\%)=\left[\frac{\sum_{i=1}^{N_{d f}} s c_{i}}{N_{d f}}\right] \times 100
$$

where $N_{d f}=22$ in each of the assessed beef retail shop.

In addition to that, total score for each design feature (TS), across all the assessed butchers in the cities was determined from total number of assessed butchers. $N_{b}$, and the given count of each butcher assessed, $S_{\mathcal{c}}$ as shown in Equation (2):

$$
T S(\%)=\left[\frac{\sum_{i=1}^{N_{b}} s c_{i}}{N_{b}}\right] \times 100
$$

where $N_{b}=29$ for Mbeya and 95 for Dar es Salaam.

\subsection{Statistical Analysis for All Beef Retailing Premises}

Next, the Kruskal-Wallis one way ANOVA by ranks test was conducted to check the possibility of having statistical difference on rating the 22 criteria grouped based on the butchers in the surveyed cities at 0.05\% significance level (95\% confidence interval) [39]. The final stage of the statistical analysis was the estimation of the density function from the observed data, i.e., number of butchers, $N_{1}$, with their respective beef quality impacting parameters, $N_{2}$. This was conducted by using the ranks in a chi-squared distribution plot designed based on degrees of freedom $k-1$, i.e., the number of indicators being compared minus 1 and with $x$ and $y$-axes labeled as $x^{2}$ and Probability Density Function (PDF), respectively. PDF of a continuous random variable, $x$, with support $S$, is an integral function $f(x)$, under three main conditions, namely: described as a PDF for continuous random variables $x$, should be positive everywhere in the support $S$, that is, $f(x)>0$, for all $x$ in $S$; and the probability of finding random variables somewhere on the real axis must be unity [39].

\section{Results and Discussion}

\subsection{Premises Building Conditions Affecting the Beef Quality}

\subsubsection{Conditions of the Doors}

Counters and entrances to the butchers in the surveyed cities have been pre- 
sented based on the observed doors' availability, construction materials and respective position as to whether in opened or closed status during the day. These features should have pest-proof doors that fitted with self-locking devices [27] [28] [29]. Self-locking devices in the doors are important as they prevent frequently touching of the handles that are invariably cleaned less often [18] [27].

The level of compliance of doors' construction materials, beef hygiene, sellers' impression to consumers and pest control and dust controlling practices were presented in Figure 3. In this respect, it was shown that only $2.1 \%$ and $10.3 \%$ of butchers in Dar es Salaam and Mbeya, respectively did not have doors indicating that the beef is accessible to dust, microbes and scavenging animals. With respect to construction materials, results indicate that entrances in more than $50 \%$ of the visited butchers complied with specification as they have glassed door which allows the customers to make a quick check of inside conditions. It also indicated that $30.5 \%$ and $37.9 \%$ of the butchers in Dar es Salaam and Mbeya have non-glassed construction materials, of which meshed doors were observed in $8.4 \%$ and $13.8 \%$ of butchers in these cities, respectively. During this assessment, $41.1 \%$ and $37.9 \%$ of butchers were complying as their doors were closed during sells. On the other hand, $56.8 \%$ and $51.7 \%$ of butchers in Dar es Salaam and Mbeya did not comply with respect to door's position during operation, indicating that the doors did not have self-locking devices fitted.

Glassed automatic doors were reported as among the appropriate material for butcher entrance as they reduce dirty trap together with the entry of both pest and dust particles to the displayed meat. Wooden doors on the other hand, are not preferred and if used they have to be coated with non-toxic, easily cleanable materials to prevent accumulation of dirt [27]. Compliance of butcher's entrance was assessed based on the availability of pest-proof doors fitted with self-locking devices [27] [28] [29]. Self-locking devices in doors are important as they prevent

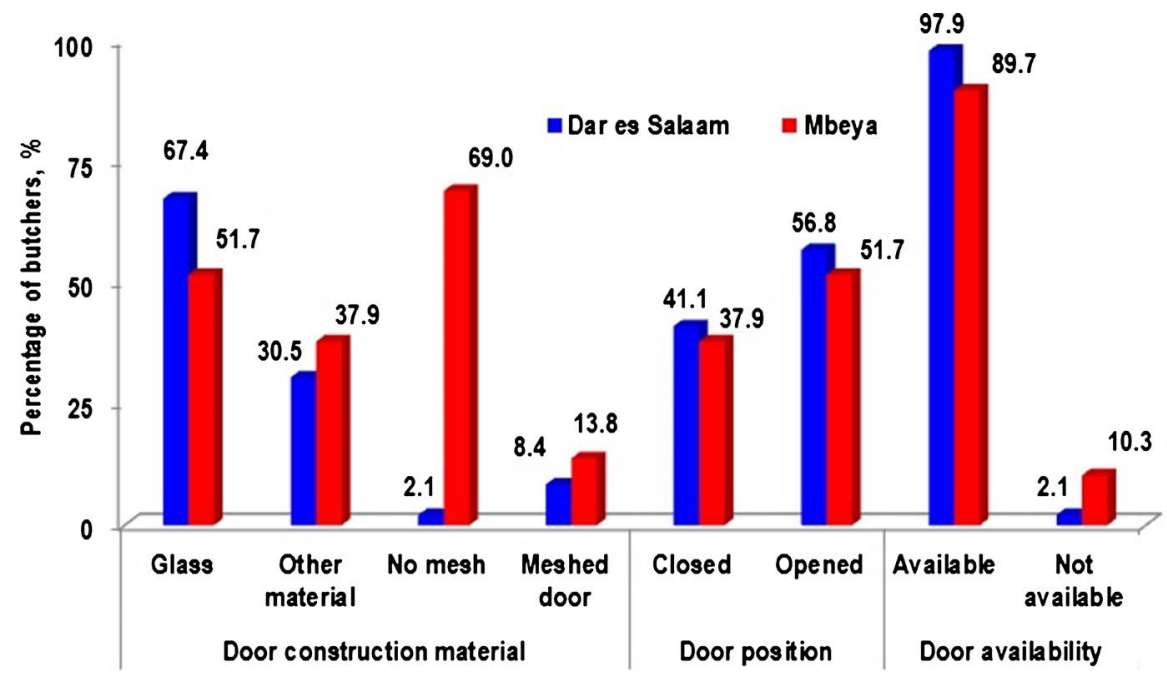

Figure 3. Distribution of butchers in Dar es Salaam and Mbeya according to doors availability, construction materials and position status during assessment $(N=95$ for Dar es Salaam and 29 for Mbeya). 
frequently touching of the handles that are invariably cleaned less often [18] [27].

Similar to this study, other studies, express not only none-glassed doors in BRPs, but the common behavior of providing over-the-counter service while the main door in open position [21]. In addition to that butcheries in Nairobi located along dusty streets or roads, and hanging meat in open space in the butchery exposes the meat to environmental contamination from dust and flies [5]. Another study that indicated non-compliance of butcher shops in developing countries as it indicated flies infestation at $78.1 \%$ due to lacking of standard fly screen or mesh at $58.9 \%$ of the surveyed butcheries [32].

Generally, when door design is used as a compliance assessment parameter for butchers, it indicates high level of non-compliance observed in butchers visited during this study. This is explained based on the observed doors in most of the butchers were fixed with inappropriate materials that can neither be cleaned nor sanitized (that is, $30.5 \%$ and $37.9 \%$ in Dar es Salaam and Mbeya, respectively). Furthermore, the level of non-compliance of doors as appropriate facilities to be fitted in BRPs is both high and variable between different places in the two cities surveyed, but also in different developing countries. Doors in most of the visited butchers do not have self-locking devices and are characterized by rough, dirty absorbing and difficult to clean surfaces. On the other hand, entries to some of the visited butchers were suitably fitted with pests and dusts protecting measures like curtains/wire meshed doors, glassed doors and doors with self-locking devices.

\subsubsection{Conditions of the Ceilings}

Compliance of ceiling of a butcher shop as appropriate premises for beef retailing was assessed based on the means at which pests, dusts and other contaminants are reduced. Ceiling should be designed and constructed in such a way that: the access of dirt, dusts and pests to beef is prevented; unable to absorb grease, meat particles and being easily and effectively cleanable [29]. Ceilings in meat selling premises were described based on the observed infrastructural and hygienic conditions in relation to beef quality during selling. Gypsum, plastered cement and hardboard were identified as materials used to construct ceilings in butcher shops during the assessment. The compliance of the identified materials, on other hand, was presented based on the level of smoothness in connection to their ability in preventing the accumulation dirt and ceiling shedding particles, which ultimately reach the beef.

It was observed further that hardboard and gypsum materials were most frequently used in construction of ceilings of the visited butchers in Mbeya and Dar es Salaam compared to other material as shown in Figure 4. Hardboard use frequently was the highest among construction materials for ceilings observed in $60 \%$ and $54 \%$ of the visited butchers in Mbeya and Dar es Salaam, respectively. The second most frequent materials used for ceilings construction in Dar es Salaam and Mbeya were gypsum (33\%) and Iron sheet (20\%). While none of the butchers in Mbeya had plastered ceilings, 6\% of the butchers in Dar es Salaam 
were constructed by this material, indicating butchers located on ground floors of multistorey buildings.

The percentage of butchers with respect to the ceiling's smoothness was higher in Dar es Salaam (48\%) than Mbeya (13.8\%) as shown in Figure 5. In connection to this, the former city has higher percentage of butcher shops with smooth ceiling construction materials, than the latter city. Results show that hardboard ceilings were rougher than gypsum boards, indicating that the latter should be preferably used for the purpose of improved beef quality in the selling points, where the buildings are not storeyed, i.e., without concrete slabs as the top.

Ceilings smoothness were also used as a parameter for assessing the compliance of the visited butcher shops in the cities as appropriate premises for selling beef. Although the compliance of the beef retailing shops as per availability of ceiling is good ( $97 \%$ for Dar es Salaam and $80 \%$ for Mbeya), the assessment based on smoothness of the available ceilings is poor with Mbeya being worse with $6.9 \%$ hardboards, $6.9 \%$ gypsum and $0.0 \%$ plastered materials than Dar es Salaam where the observations were $20.0 \%, 26.3 \%$ and $4.2 \%$ of respective
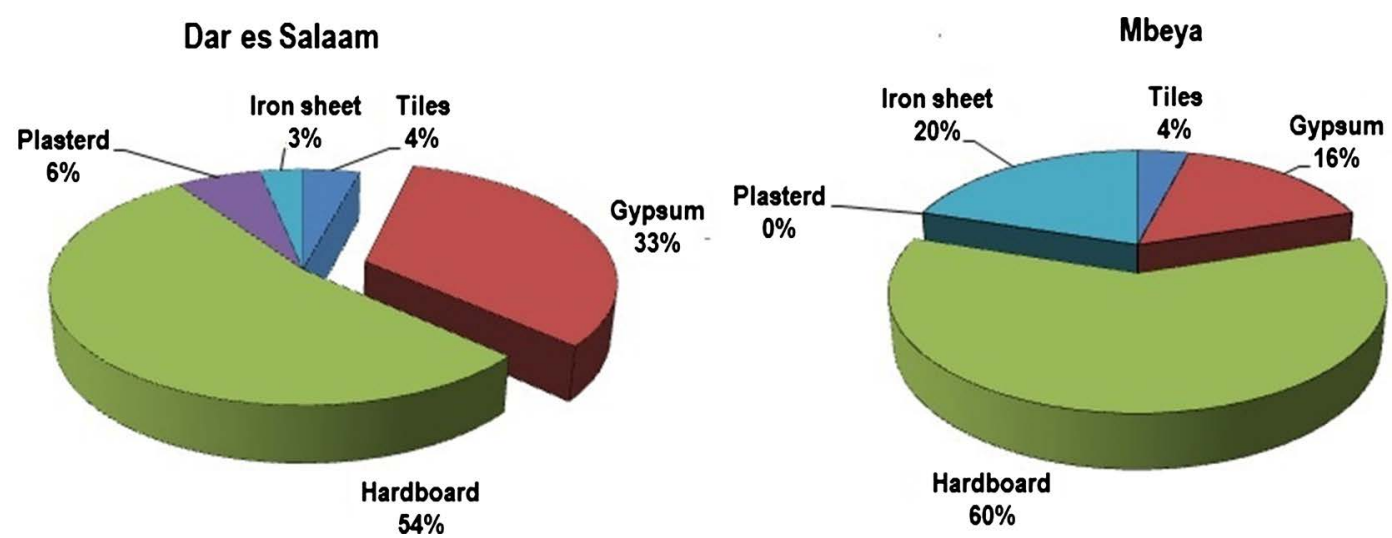

Figure 4. Distribution of ceiling construction materials in butchers in Mbeya and Dar es Salaam $(N=95$ for Dar es Salaam and 29 for Mbeya).

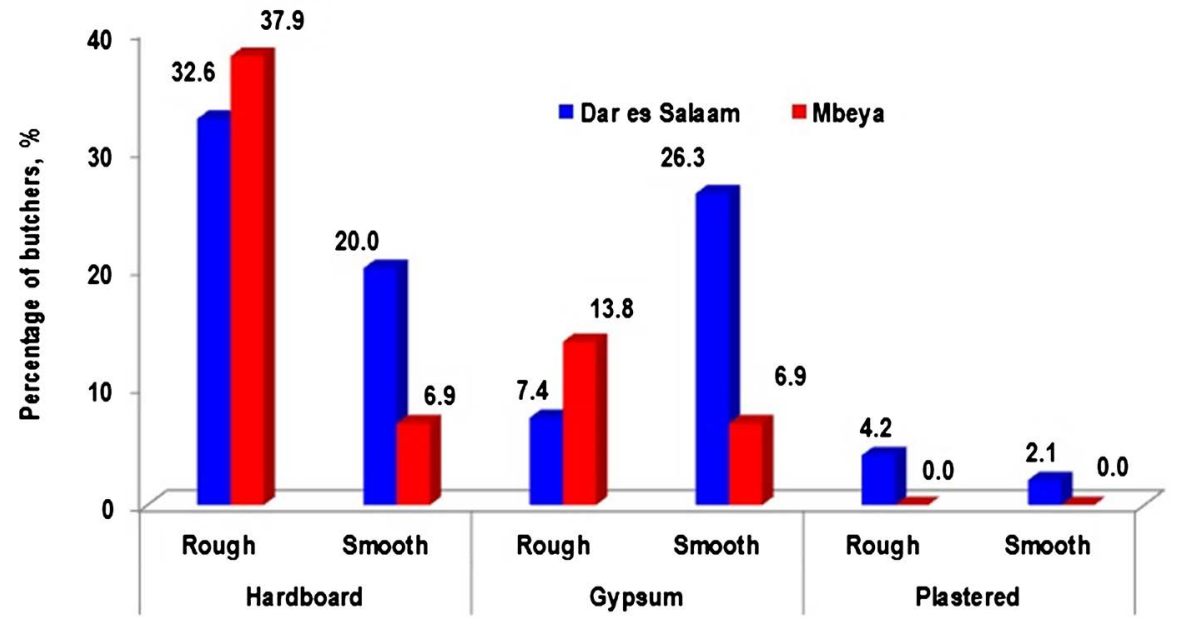

Figure 5. Distribution of rough ceilings in butchers based on the type of construction materials ( $N=95$ for Dar es Salaam and 29 for Mbeya). 
construction materials. Moreover, Dar es Salaam was observed to have higher percentage of butcher shops that were not only unsealed, but also without appropriate materials compared to Mbeya.

A similar study was conducted in Ethiopia showing that one third of butcher shops were without ceiling, a situation that hinders cleaning [23]. The study on good hygiene practice in Butwal municipality has also shown that BRPs that $97.4 \%$ of the meat handlers were completely not care on ceilings and ventilating facilities [26]. Non-compliance to the requirement of walls and ceilings for butcher shops was also reported by other studies, with literature showing further that the business of selling meat and meat products was conducted in unsanitary environment such as open shelters and unclean kiosk butcheries [5].

Finally, when ceiling conditions are used as a compliance assessment parameter of butchers, it indicates high level of non-compliance observed in butchers visited during this study. This is attributed to poor conditions of the observed roofs in most of the butchers which were fixed with materials that can neither be cleaned nor sanitized. Among the complied meat selling premises, Dar es Salaam had high composition of butchers that have ceilings that are constructed with gypsum materials (which provides smooth and cleanable surface) compared to Mbeya. Butcher shops in Mbeya, on the other hand, were observed to have high percentage of butchers with the appropriate hardboard for beef retailing activities.

\subsubsection{Conditions of the Walls}

Presentation of the compliance for the walls in the surveyed BRPs, as appropriate meat selling premises was further categorized based on the type construction materials and hygienic conditions. In this study, gypsum, plastered cement and tiles were the construction materials observed in most of the visited butcher shops. The compliance of the observed materials, on other hand, was presented based on the level of smoothness in connection to their ability in preventing the accumulated dirt and walls' shedding particles.

About $91.6 \%$ of the visited butchers in Dar es Salaam were observed to have tiled walls while the corresponding fraction was $55.2 \%$ for Mbeya as shown in Figure 6. The percentage of butchers with plastered walls on the other hand, was generally low with Mbeya having relative high percentage of smooth plastered walls (24.1\%) compared to Dar es Salaam. Gypsum is not recommended materials for walling in BRPs, and according to this study, such materials were observed to a very small extent in both cities.

Figure 7 compares the frequency distribution of different wall hygienic conditions and maintenance status for BRPs Dar es Salaam and Mbeya. The results indicate that more than $50 \%$ of butchers in both cities were in good condition being properly fitted with the appropriate construction materials. About $62.1 \%$ of butchers observed in Mbeya were appropriately cleaned compared to 50.5\% found in Dar es Salaam. Poor hygienic conditions depicted in butchers due to dirty walls (49.5\% in Dar es Salaam and 37.9\% in Mbeya, respectively) indicate a challenge to the beef quality. Moreover, a wall in cracked conditions $(36.8 \%$ in 


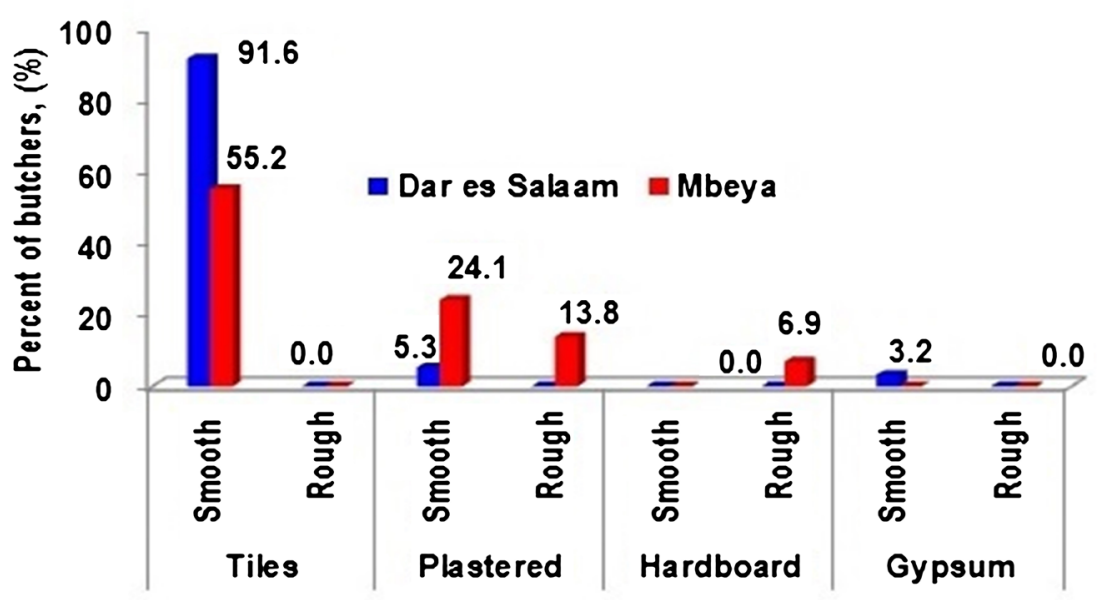

Figure 6. Surface conditions for different wall construction materials observed in the butchers $(N=95$ for Dar es Salaam and 29 for Mbeya).

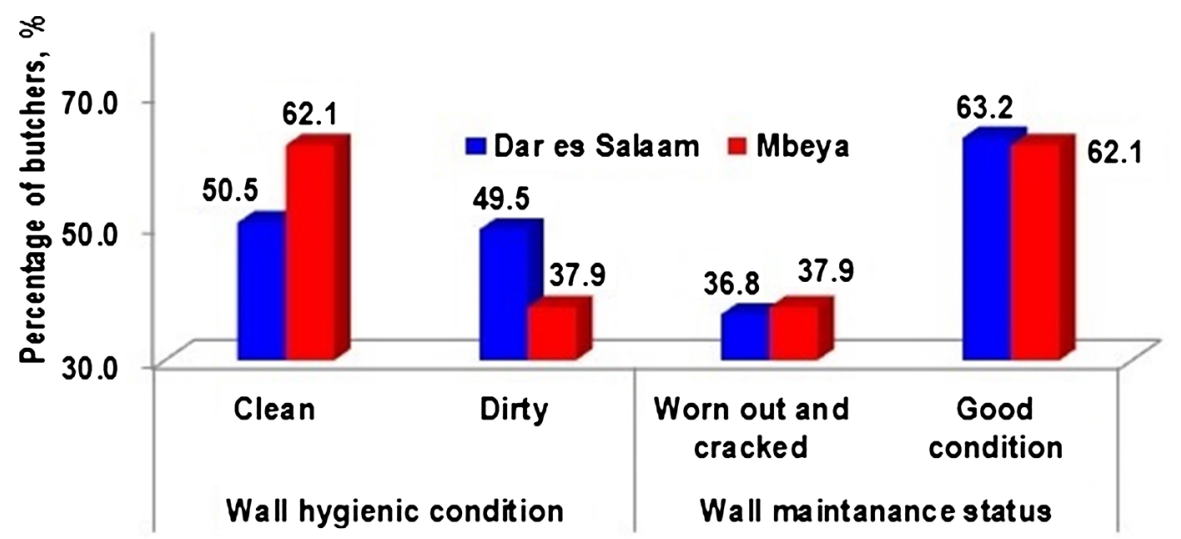

Figure 7. Distribution of wall hygienic conditions and maintenance status in Dar es Salaam and Mbeya ( $N=95$ for Dar es Salaam and 29 for Mbeya).

Dar es Salaam and 37.9\% in Mbeya) indicates a probability of hosting pests and dust, also a challenge to beef quality.

The presented compliance was assessed based on [27] [28] that indicate that butchers' walls should be smooth, with neither flaking paint nor crevices to harbor pests. The assessment reported by other studies [31] was based on the similar indicators, during which the results indicated walls for butcher shops not painted and too dusty to attract beef consumers. Similarly, wall surfaces of BRPs in Butwal, Nepal were not properly maintained following the responses of $97.4 \%$ of the assessed meat handlers [26]. The surface of walls should be made using impervious materials with no toxic effect in intended use [31]. This is also supported by a study reported by other authors who indicate that cracked, rough and non-painted walls as areas susceptible for bacteria residing [31] [32]. Generally, butchers' walls if taken as one of the compliance assessing parameters indicate high level of non-compliance in the visited cities. This is explained by not only the observed installed construction materials but also cracks and dirty walls with accumulated shedding materials. 


\subsection{Beef Processing, Splitting and Weighing Area Design}

\subsubsection{Design Features of Beef Processing Areas}

The level of compliance observed beef processing facilities in the visited cities are presented here based on construction materials and maintenance status of beef processing areas. Construction materials that were observed during this survey are wood, tiles, concrete and aluminum. Results of maintenance as a compliance assessment parameter on the other hand, is presented based on hygienic and appearance of the beef processing area. Assessment results for beef processing facilities on compliance of butchers in Dar es Salaam and Mbeya as appropriate premises for selling beef are presented based on the construction material of their processing blocks, maintenance status and the hygienic status in the respective processing areas. With exception of wood material as processing blocks, the general results indicate that the compliance of butchers in the visited cities are not similar as shown in Figure 8.

Among the surveyed butchers, the complied butchers with respect to tiled beef processing areas in Dar es Salaam and Mbeya were 50.5\% and 31.0\%, respectively. The smoothness of processing areas made up of concrete material was opposite, being high for Mbeya (27.6\%) compared to Dar es Salaam (21.1\%). Another variation of the results is observed on the aluminum as a beef processing construction material on which high percentage of the visited butchers in Mbeya were observed to have smooth aluminum material (20.7\%) compared to Dar es Salam (13.7\%). The study indicated also that less than $10 \%$ of the visited butchers have wooden processing materials. Among the butchers with wooden processing materials, Mbeya had relative higher non-complied butchers (6.9\%) with rough surfaces than Dar es Salaam that had $1.1 \%$. In general, construction material as a compliance assessing parameter indicates high level of compliance since beef processing areas in $86.1 \%$ and $79.3 \%$ of the surveyed butchers in Dar es Salaam and Mbeya, respectively, were appropriate constructed.

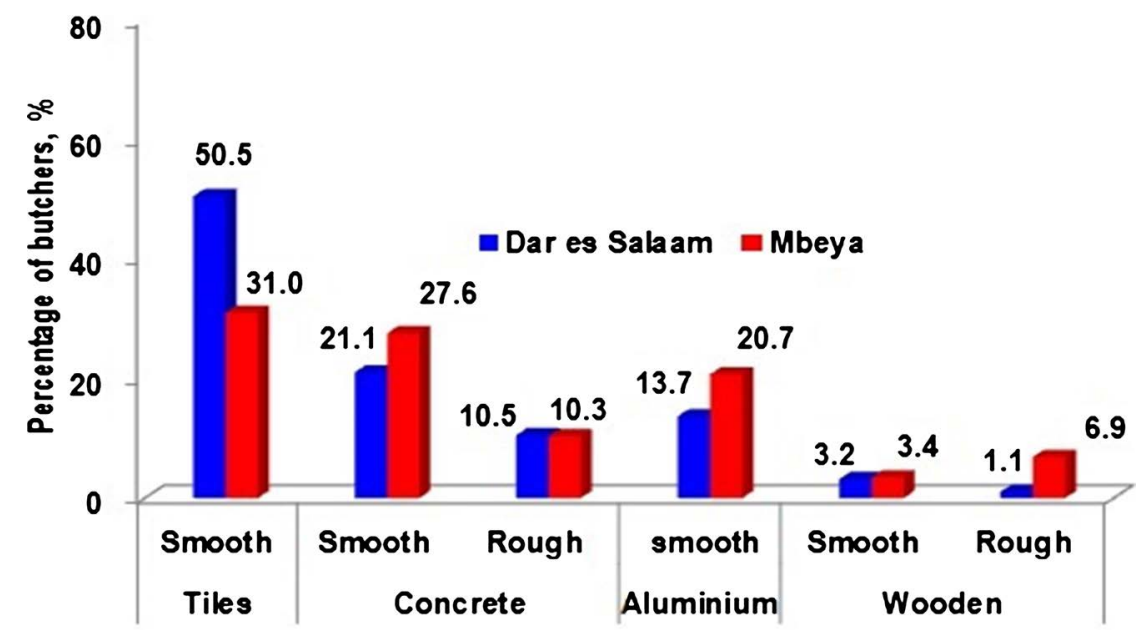

Figure 8. Frequency distribution of smoothness and roughness of the beef processing areas based on type of construction materials in butchers $(N=95$ for Dar es Salaam and 29 for Mbeya). 
There is variability in the level of compliance of butchers in the visited cities in terms of hygienic condition and appearance as shown in Figure 9. High percentages of the visited butchers in Mbeya were clean (58.6\%) compared to those visited in Dar es Salaam (50.5\%). The study also indicated that in Dar es Salaam the butchers were observed to have high percentage of butchers (52.6\%) with broken beef processing areas compared to Mbeya (34.6\%).

Broken beef processing areas should be clean and appropriately maintained immediately for preventing pests and harmful microorganisms harboring. With regards to cleanliness and maintenance status, $58.6 \%$ and $65.5 \%$ of butchers in Mbeya, respectively, were complied with specifications, indicating a higher compliance than in Dar es Salaam. Dar es Salaam had 52.6\% of butchers in Dar es Salaam had worn-out and or cracked beef processing areas compared to $34.5 \%$ in Mbeya. This is similar to other studies that have shown that meat processing at retail level is likely to have huge contribution of contamination in the supplied beef [17] [26]. In connection to this, the study on hygienic practices in retail meat shops in Butwal Municipality, Nepal has shown that $96.8 \%$ of the meat handlers were unhealthily handling money while processing meat [26].

\subsubsection{Beef Storage Infrastructure in the Beef Retail}

In this study, compliance of beef storage was presented based on type, availability, hygiene and storage practices of the facilities used for beef storage the retailing shops. While the assessment with respect to types of storage facilities was presented based on the applicability of freezers only, refrigerators only and variety storage facilities (refrigerators and freezers), hygiene was presented based on cleanliness and dirtiness of the observed storage facilities. The butchers' assessment results on the storage practices was then presented based on whether beef stored separate only or combined with perishable food. Lastly, it was the presentation of the assessed butchers with respect to whether storage facilities were available or not.

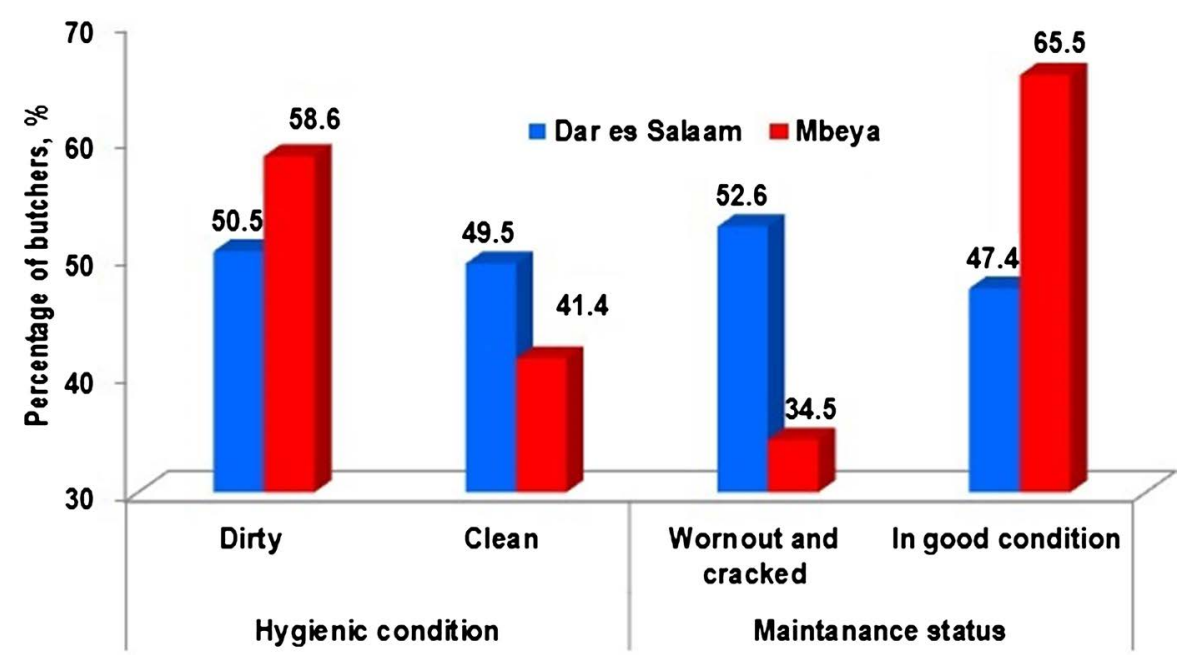

Figure 9. Frequency chart for hygienic and maintenance status of the beef processing areas in butchers ( $N=95$ for Dar es Salaam and 29 for Mbeya). 
With respect to types of storage facilities, butchers with freezers only were the highest at $64.2 \%$ and $51.7 \%$ for Dar es Salaam and Mbeya, respectively as shown in Figure 10. In addition to this, butchers with refrigerators only and variety storage facilities (refrigerators and freezers) were $8.4 \%$ and $16.8 \%$, respectively. On the other hand, none of the butchers in Mbeya had either refrigerators or variety of storage facilities during the assessment.

Furthermore, $48.3 \%$ of butchers in Mbeya were selling beef without refrigeration as compared to $10.5 \%$ of butchers in Dar es Salaam. This is interpreted as resulted from the difference in ambient temperature between the cities as shown in other studies during which: the former city has a moderate climate with temperature that is less than $25^{\circ} \mathrm{C}$ [40]; and the latter one is hot humid climatic city with the mean annual temperature of $30^{\circ} \mathrm{C}$ [41]. Similarly, the hygienic assessment of meat retailing in Butwal, Nepal has shown that $21.1 \%$ and $71.6 \%$ of the surveyed BRPs were operating without storage facilities and covering the meat with red cloths, respectively [26]. In addition to that the study in Kenya where beef was stored in refrigerators in $39.4 \%$ in Isiolo County where ambient temperature is high as compared to Nairobi County that have $11 \%$ butcher with storage facilities [5]. It was also indicated that $72.5 \%$ of beef retailing shops in Morogoro Municipality were operated without storage facilities during which meat that was left were normally transferred to another shops where storage facilities are available [10] [33].

\subsection{Design Features of the Beef Splitting Instruments}

Carcasses or beef processing instruments are presented as a compliance assessment parameter based on splitting facilities, cutting boards and or butchering block together with hanging hooks. It includes assessing the means in which retail meat handling areas has potential to contribute to contamination of the beef before and after processing. Motorized saw being an appropriate beef processing

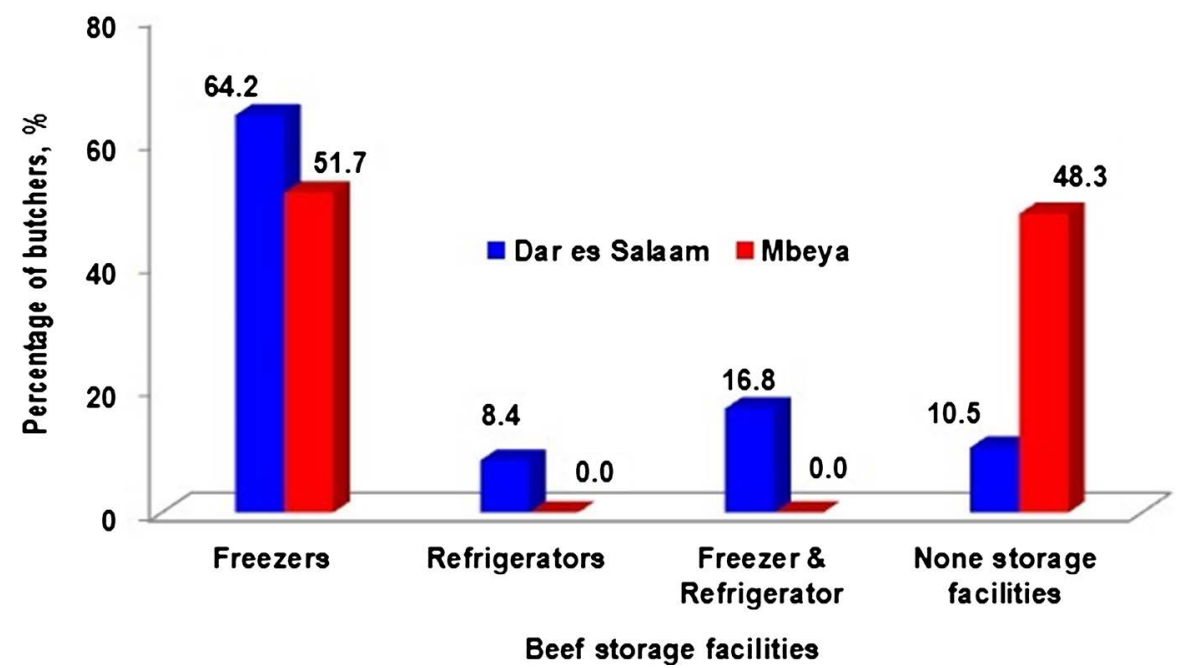

Figure 10. Frequency distribution of storage facilities based on both their respective availability and types ( $N=95$ for Dar es Salaam and 29 for Mbeya). 
facility was observed in $40.9 \%$ and $34.5 \%$ of the butchers in Dar es Salaam and Mbeya, respectively as shown in Figure 11. Use of Hand axe was observed in $40.9 \%$ and $89.7 \%$ of the visited butchers in Dar es Salaam and Mbeya, respectively. Moreover, the use of Panga for splitting carcasses was observed in $14.8 \%$ and $48.3 \%$ of the butchers in Dar es Salaam and Mbeya, respectively.

Compliance of cutting facilities in meat retailing shop is measured based on the applicability of the appropriate meat cutting material [27] [28]. Similarly, a study in Kenyan cities indicates appropriate and cleaned butchery utensils in only $34 \%$ and $60 \%$ of the surveyed meat retailing shops in Nairobi and Isiolo counties, respectively [5]. Other studies in this respect, indicates non-compliance based on this assessment criteria following $95 \%$ of the workers in the visited meat outlets were chopping bony meat with hand axe [10].

Non-compliance as per beef processing/cutting board during which $44.6 \%$ and $75.9 \%$ of the butchers in Dar es Salaam and Mbeya, respectively, were using an improved log from a tree trunk, locally known as "kigogo" as shown in Figure 12. On the other hand, compliance as per this parameter is presented as $41.3 \%$ and $34.5 \%$ of the beef retailing shops in Dar es Salaam and Mbeya, respectively, were using appropriate cutting boards on wooden tables, that is either made of aluminum block or wooden materials. It was also shown that $65.2 \%$ and $58.6 \%$ of butchers in Dar es Salaam and Mbeya were using appropriate hanging hooks made of stainless steel during beef retailing. Rusting iron hooks are not acceptable as they act as source of beef contamination, which was observed in $34.8 \%$ and $41.4 \%$ of butchers in Dar es Salaam and Mbeya, respectively.

Meat should be processed in non-dark, smooth cutting and cleanable cutting blocks from one among the following materials: plastics, concretes, wood and any other food grade materials [29]. In connection to this, a study in Morogoro Municipality, Tanzania, reveals applicability of non-complied wooden cutting blocks in many retail outlets [10]. It is further indicated that most of the meat

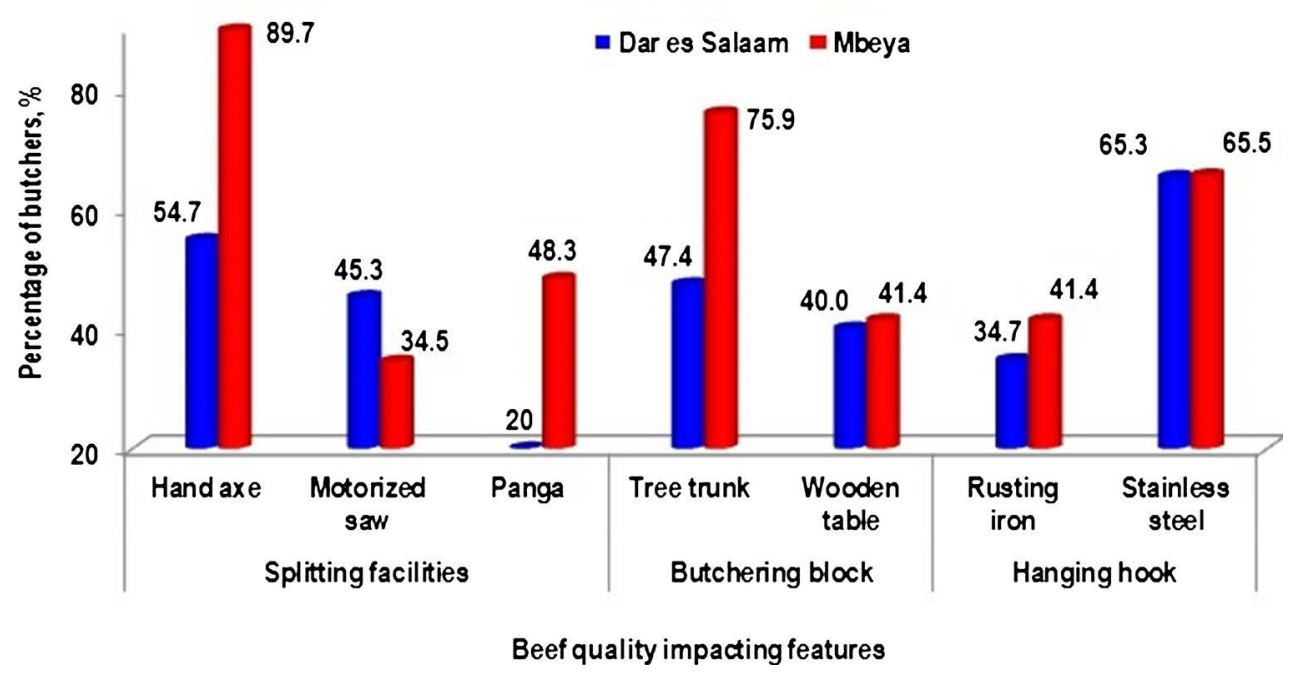

Figure 11. Distribution of butchers according to the beef cutting and splitting facilities used ( $N=$ 95 for Dar es Salaam and 29 for Mbeya). 
handlers were chopping bony meat on cutting logs which were observed to be in poor hygienic conditions. Compliance measurement as per carcasses/beef hanging hook is presented based on the material of construction as to whether made of rust free material like stainless steel or not [28]. Compliance assessment based on type of butchering blocks and materials of construction for hanging hook in the butchers indicates high level of non-compliance, hence high chance of cross-contamination between beef and meat handlers and also from the environment. Furthermore, the chance for contamination was higher in Mbeya than Dar es Salaam due to the high percent of non-compliance in the former city.

\subsection{Statistical Evaluation of Compliance Data in the Retailing Premises}

\subsubsection{Results for Total and Overall Scores}

Total scores computed or selected butcher design characteristics R1 to R22 from 29 and 95 BRPs for Mbeya and Dar es Salaam cities, respectively were presented in Figure 12. It is presented based on two conformance criteria, i.e., at 1 scored level for complied premises and zero level as none-conformed butchers. The compliance is ranged at 3 and 12 level for the former city and 5 and 13 scored level for the other city. In general, compliance for BRPs in Dar es Salaam is higher than Mbeya. This finding is quantified by other studies that have shown that the demand for suitable beef with respect to the advanced retailing premises is higher in big cities like Dar es Salaam than other cities [20] [21].
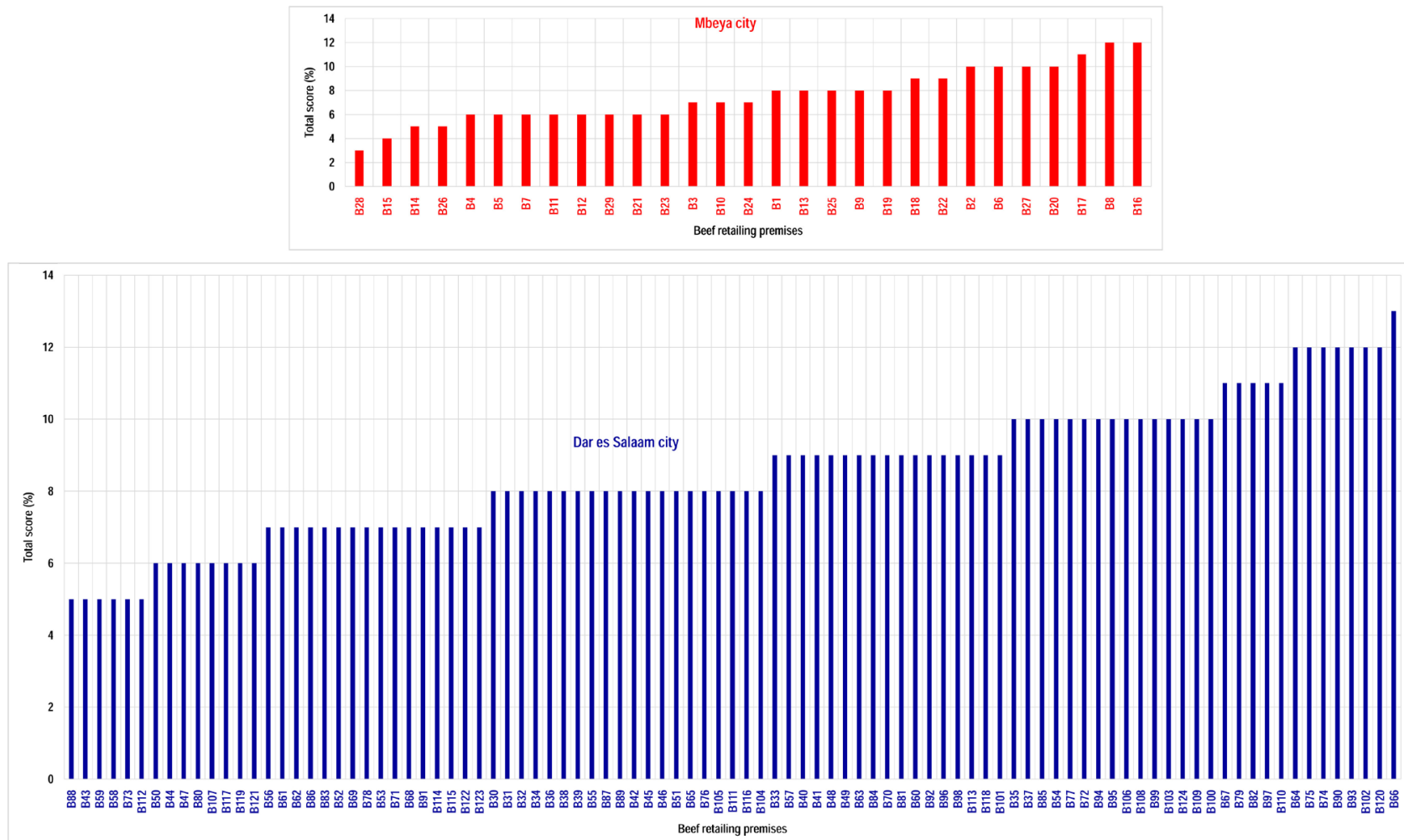

Figure 12. Comparison of the total scores for butchers in Dar es Salaam city (B30-B129 are butchers in Dar es Salaam). 


\subsubsection{Statistical Analysis of the Total Scores}

The compliance estimates based on data sets of butchers in Dar es Salaam and Mbeya were statistically presented by using PDF plot as shown in Figure 13. The plots were accepted as PDF as they were comply with the three main requirements, i.e., non-decreasing, right continuous and asymptotically bounded in 0,1 behaviors.

The total scores of each butcher across the maximum 22 points (corresponding to all the evaluated BQIF) were ranged between 5 and 16 points in both Dar es Salaam and Mbeya. Two peaks in connection to this were observed as $25 \%$ of the assessed butchers in the former city scored 8.3 and 12.2 total points. Whereas, the two peaks in the latter city were also observed as the approximated $24 \%$ and $17 \%$ of butchers had 8.9 and 14 total scored points. The troughs with respect to this assessment were observed in Mbeya where 10\% and 7\% of the assessed butchers scored 9 and 13 total points, respectively. Another trough was also observed in Dar es Salaam where 12\% of the assessed butchers scored 11 total points. Another remarkable feature at this point of study is the maximum and minimum percentage of the assessed butchers in the plot is equal in both cities. Bimodal behavior of plots observed in this study as another interesting feature, was reported as due to the mix-up of data from different populations [13].

Similar to this study, the assessment on sanitation and hygiene meat handling practices in Nairobi and Isiolo counties indicated the same patterns of results on which butchers operators did not adhere to the food quality specification [5]. Likewise, other studies have reported the same pattern on contamination due to insufficient hygienic practices and improper handling of meat in retail shops in different locations [14].

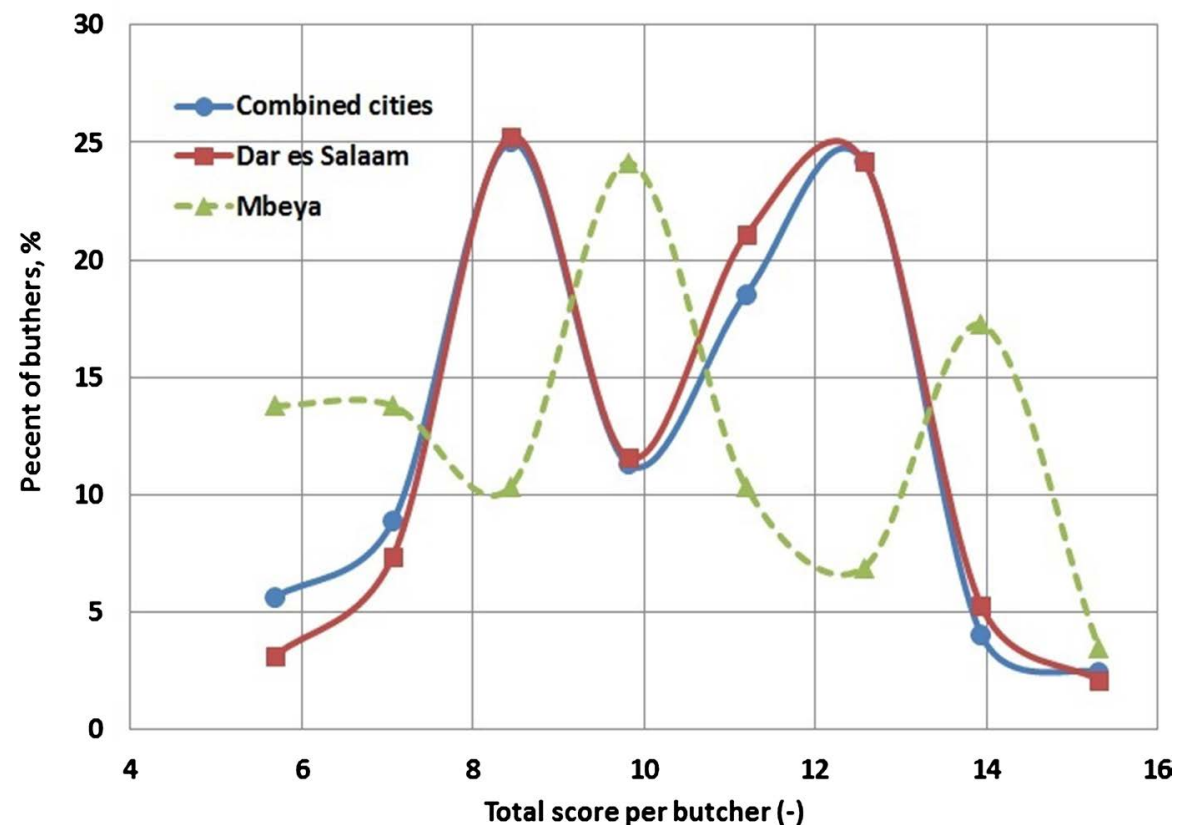

Figure 13. Probability density functions of the total score per butcher or combined data and or each city ( $N_{1}=29$ for Mbeya and 95 for Dar es Salaam). 


\subsubsection{Control Chart for Butchers' Total Scores Data}

Compliance of butchers in the surveyed cities was presented by using quality control charts as indicated in Figure 14. The figure shows the quality control of a total of 124 combined data obtained from the surveyed cities on the responses (based on the established criteria, i.e., 1 for conformity and 0 for non-conformity) to the pre-listed variables on the compliance assessment of beef retailing shops. This is a graph of complied individual butchers plotted on a format that includes statistical process limits set at Xbar +2 with standard deviation (2.36) together with lower control limit (5.51) and upper control limit (14.96) as indicated in Table 2.

Figure 14 shows a quality control run chart that was designed to test the null hypothesis that states that all the surveyed butchers in Dar es Salaam and Mbeya

Table 2. Statistical analysis summary for total scores per butcher in Dar es Salaam and Mbeya

\begin{tabular}{cccccc}
\hline Statistical parameters & Combined & Dar es Salaam & Mbeya & \multicolumn{2}{c}{ Control limits: \pm 2} \\
\hline Number of samples & 124 & 95 & 29 & (Dar es Salaam + Mbeya) & 124 \\
Standard deviation & 2.36 & 2.23 & 2.68 & & 14.96 \\
Mean & 10.23 & 10.43 & 9.59 & Xbar +1 & 12.60 \\
Minimum & 5 & 5 & 5 & X-bar & 10.23 \\
Maximum & 16 & 16 & 15 & Xbar-1 & 7.87 \\
Range & 11 & 11 & 10 & Xbar-2 & 5.51 \\
\hline
\end{tabular}
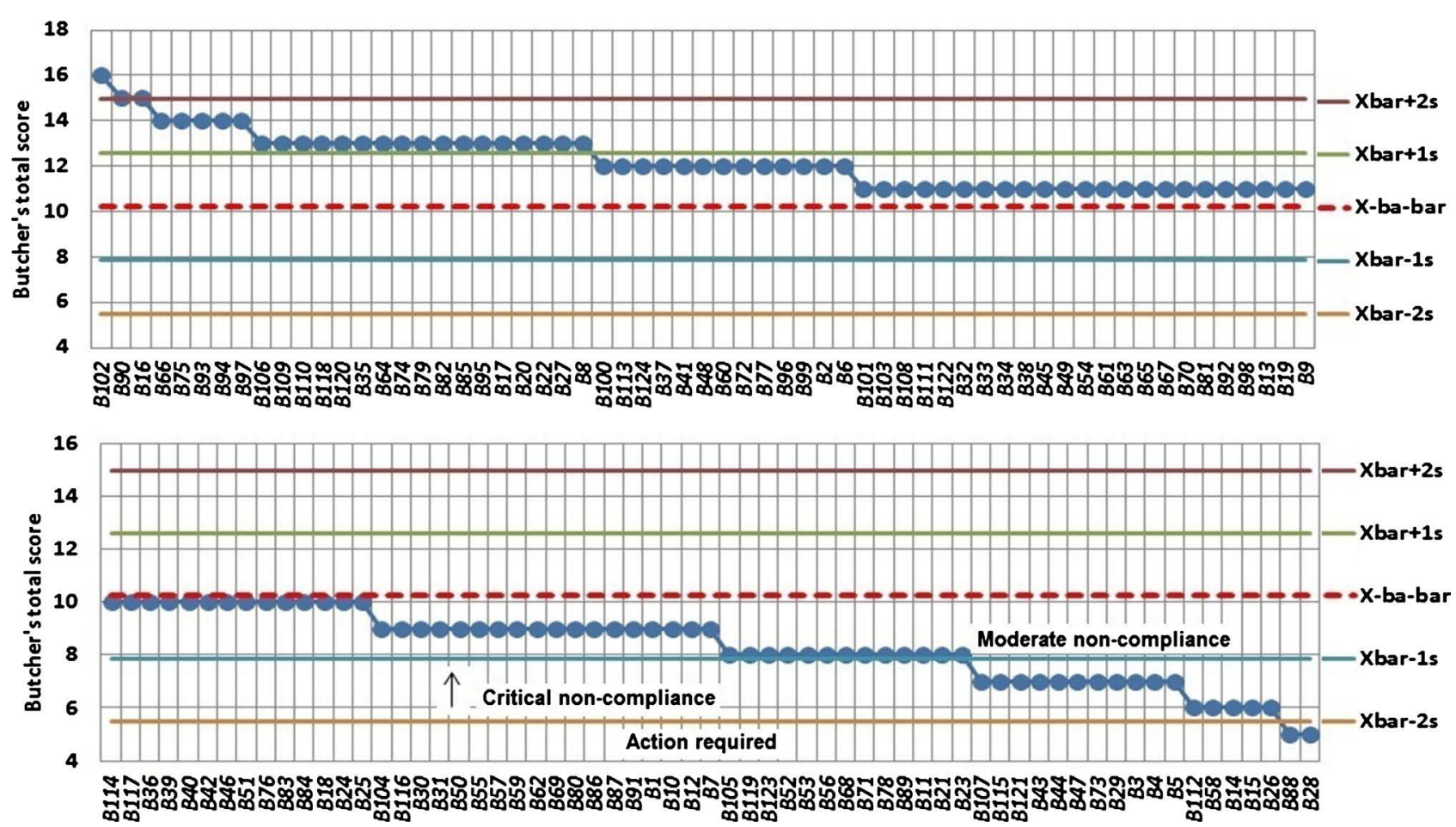

Figure 14. Running charts for butchers total scores data from Dar es Salaam and Mbeya cities (B1-B29 are butchers in Mbeya and B30-B129 are butchers in Dar es Salaam). 
comply with the food quality requirements. Butchers with the total of score below $\mathrm{x}$ bar and above Xbar-1 were regarded as moderate noncompliance which included a total of 41 BRPs (21 in Dar es Salaam and 20 in Mbeya). The BRPs with a total score between Xbar-1 and Xbar-2 were regarded as falling into a critical non-compliance, which included a total of 52 butchers (27 butchers in Dar es Salaam and 25 in Mbeya). Two butchers B88 and B28 scored below Xbar-2 insisting action by regulatory authorities. About 56 scored above $\mathrm{x}$ bar for which 36 and 13 butchers were from Dar es Salaam and Mbeya, respectively. This non-conformance is less than intolerance due to Salmonella in 7\%, and 9\% of the surveyed butchers in Pakistan and Ethiopia, respectively [11] [12] [31].

\subsubsection{Analysis of Compliance Index Data for R1 to R22}

The observed conditions in beef retailing shops were statistically analyzed based on their respective infrastructural conditions against raised hypotheses in connection to food specifications. The presentation includes analysis of both level of their respective compliance and correlation of beef retailing located in different wards. The approach adopted for data presentation and analysis is in tandem to other studies [38] for assessment of compliance with disclosure requirements of IAS 16. The analyzed results from the survey of beef retailing premises are presented in tables or clustered columns of total observed scores and frequency distribution curves adopted with modification from other literature [30]. In Table 3 , the distribution results were also presented based on the statistical comparison parameters. This includes frequency and cumulative frequency statistical parameters that were categorized based on four compliance index levels and named as $\mathrm{A}, \mathrm{B}, \mathrm{C}$ and $\mathrm{D}$.

Results based on these statistical parameters were further elaborated by using frequency distribution and cumulative frequency plots as shown in Figure 15. It was indicated that, the highest frequency was in category B at 40 - 49 compliance index level, i.e., the third highest scored categorized group, with eleven (11) wards, followed by group C that ranged at $50 \%-69 \%$, the second top most categorized level. The third level with three wards was group A, with $20 \%-39 \%$ level, i.e., which is the fourth categorized group. In addition to that, none of the surveyed wards was in group D, i.e., 70 - 100 the highest categorized group.

\subsubsection{Analysis of Compliance Index Clustered by Wards}

Figure 16 compares the compliance index values for different wards in Dar es

Table 3. Result on the summarized compliance analysis.

\begin{tabular}{cccccc}
\hline Category & $\begin{array}{c}\text { Compliance } \\
\text { index levels }\end{array}$ & $\begin{array}{c}\text { Frequency } \\
\text { (number of wards) }\end{array}$ & $\begin{array}{c}\text { Cumulative } \\
\text { frequency }\end{array}$ & $\begin{array}{c}\text { Frequency } \\
\text { (wards) \% }\end{array}$ & $\begin{array}{c}\text { Cumulative } \\
\text { frequency \% }\end{array}$ \\
\hline A & $20-39$ & 3 & 3 & 16.7 & 16.7 \\
B & $40-49$ & 11 & 14 & 61.1 & 77.8 \\
C & $50-69$ & 4 & 18 & 22.2 & 100.0 \\
D & $70-100$ & 0 & 100 & 0.0 & 100.0 \\
\hline
\end{tabular}




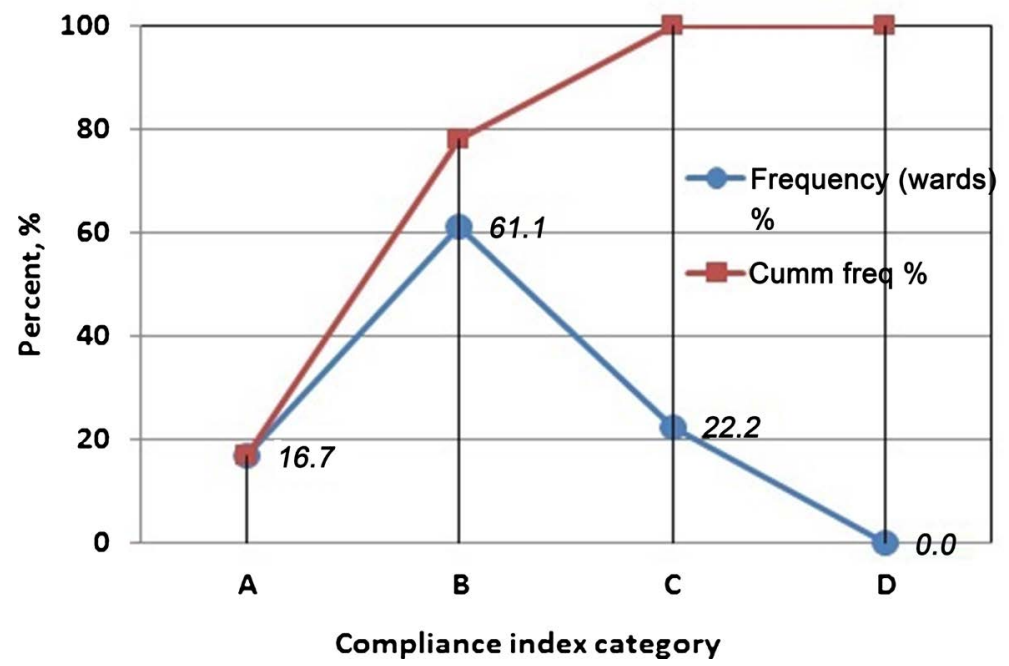

Figure 15. Frequency distribution and cumulative frequencies of the compliance index levels.

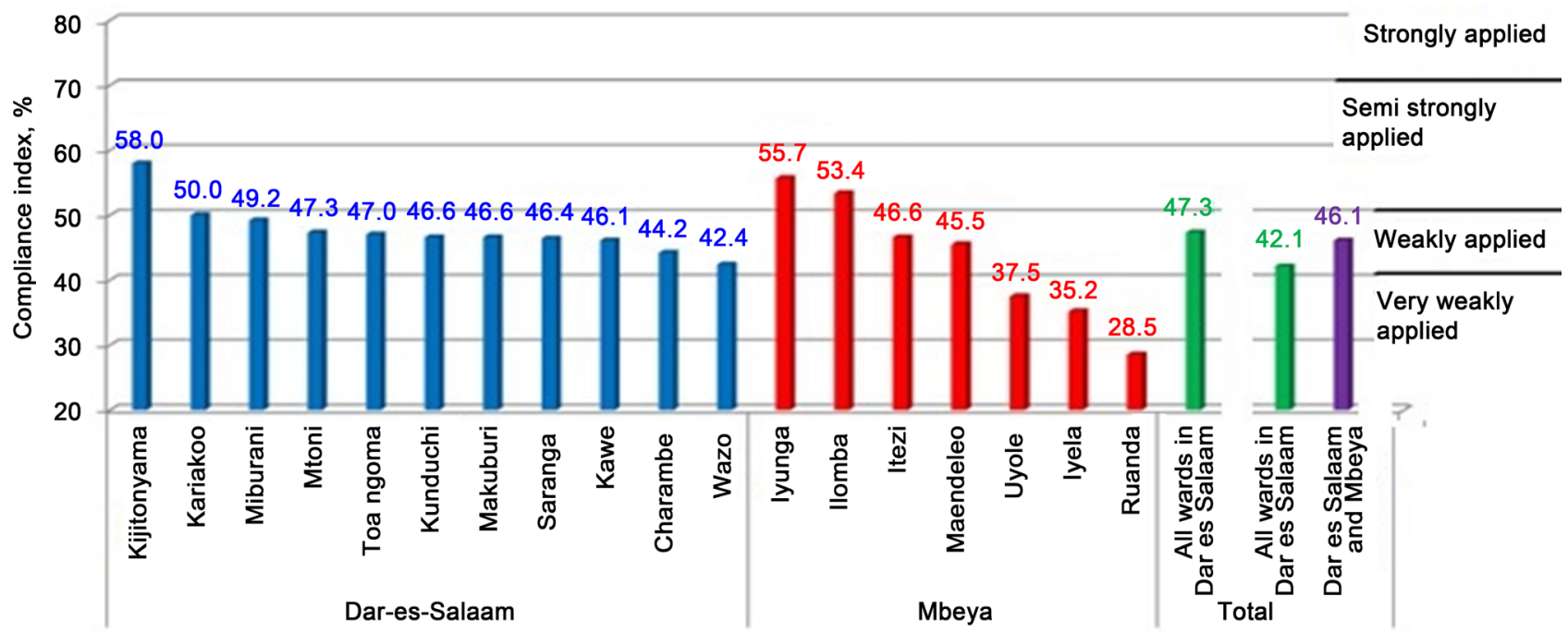

Figure 16. Comparison of compliance levels of butchers arranged according to their respective wards $(N=95$ for Dar es Salaam and 29 for Mbeya).

Salaam and Mbeya based on 989 and 278 observations in the beef retailing premises. In this study the top most wards with 50 and higher compliance indices in descending orders were Kijitonyama (58.0\%), Iuynga (55.7\%), Ilomba (53.4\%) and Kariakoo (50.0\%). On the other hand, Ruanda in Mbeya was the lowest scored ward at $28.5 \%$ compliance index. The total scored level for both cities was $46.1 \%$, the compliance index that deduced from $42.1 \%$ and $47.3 \%$ compliance indices scored from the surveyed butchers in Mbeya and Dar es Salaam.

The scored levels in Dar es Salaam ranged between $42.4 \%$ and 58\% with Wazo being the lowest ranked and Kijitonyama the highest scored ward. On the other hand, the range in Mbeya was between 55.7\% and 28.5\%, in which Iyunga and Ruanda being at the highest and lowest ends, respectively. Results in this study were further presented by using the superimposed plots in which the findings 
from Mbeya and Dar es Salaam were compared as detailed in the Figure. It was noted that butchers in two wards, one from Mbeya and the other from Dar es Salaam had compliance index of 55\% and above. Furthermore, the level of compliance in Mbeya were scattered distributed between 25\% and 55\% compliance indices. Whereas, the scored levels of most of the surveyed butchers in Dar es Salaam were narrowed at the $45 \%$ and $55 \%$ compliance index range.

With regards to the first hypothesis of this study and data analysis by using this model, it was deduced that: this model is semi-strongly applied to butchers in Kijitonyama (58\%), Kariakoo (50\%), Iyunga (55.7\%) and Ilomba (53.4\%); weakly applied in eleven butchers; and very weakly applied in Uyole (37.5\%), Iyela (35.2\%) and Ruanda (28.5\%) wards. Therefore, based on these remark, it is deduced that, the listed BRPs in both cities leads to an overall conclusion that the butchers were weakly complied at $42.1 \%$ and $47.3 \%$ compliance indices levels for Mbeya and Dar es Salaam, respectively. Generally, the compliance based on these values in not satisfactory. This is due to the existence of more stringent provisions in food technical requirements than actual conditions in the field in beef quality management. The implication is that we failed to reject the null hypothesis which hypothesizes that the visited beef retailing points do not comply with the technical requirements. The levels of compliance observed from test of hypotheses were lower than that observed in other researches on compliance in other parts of the developed world. This is in line with other studies in their findings that indicate poor handling during which carcasses, quarters, unwashed offal, and other items placed together on the floor or dirty concrete or wooden tables in retailing shops, increasing the microbial contamination of the meat [9] [10] [17]. This study was also corresponding to the findings that indicated that contamination sources of beef are more likely to be associated with insufficient hygienic practices and improper handling of meat in retail shops [17] [20] [22] [23] [24].

\subsection{Kruskal-Wallis Based Statistical Interpretation}

A Kruskal-Wallis $\mathrm{H}$ test was conducted to determine if the compliance of beef retailing shops that categorized based on the surveyed wards was different for twenty two (22) designed features (twenty two groups) as shown in Table 1. Table 4, on the other hand summarizes Kruskal-Wallis test results for the designed features. The Kruskal-Wallis $H$ test showed that there was statistically significant difference in compliance between the twenty two designed features in both Dar es Salaam and Mbeya. In the former city, $H=121.539$ is in critical region bounded by 32.671 , so the hypothesis of equal medians of the scored in the assessed designed features was rejected. Similarly, the hypothesis of equal medians of the scored levels in the assessed designed features in Mbeya was rejected based on the $H=74.852$ being in critical region bounded by 32.671 . Generally, gives sufficient evidence to reject the claim that the scored levels of the designed features of the assessed beef retailing premises grouped based on the surveyed wards have equal medians. At least one of the medians appears to be different from the other. 
Table 4. Kruskal-Wallis test results for the assessed beef retailing premises.

\begin{tabular}{ccc}
\hline Statistic parameters & Dar es Salaam & Mbeya \\
\hline Total number of assessed values & 242 & 154 \\
Test statistic, $H$ & 121.539 & 74.852 \\
Number of samples, $k$ & 22 & 22 \\
Degree of freedom, $(k-1)$ & 21 & 21 \\
Critical, $H$ & 32.671 & 32.671 \\
Number of observations, $n$ & 11 & 7 \\
\hline
\end{tabular}

\section{Conclusion and Recommendation}

The study concludes that, BRPs in the surveyed cities were characterized by high level of non-compliance of the assessed doors and ceilings. Walls in most of these beef selling premises were not only poorly maintained but inappropriately painted and too dusty to attract beef consumers. It was also shown that, the level of compliance with respect to beef storage and splitting in the surveyed BRPs is higher for Dar es Salaam than Mbeya. All the surveyed cities were completely not appropriate with respect to the assessed meshed doors and staff exchanging room as their compliance index was at the lowest category of compliance index.

The study revealed that the compliance of the BRPs according to their respective wards is not uniform as Kijitonyama, Iyunga, Ilomba and Kariakoo were identified in the semi strongly applied top most achieved level of compliance index in this study as compared to the other wards. Ruanda, on the other hand, was ranked as the lowest conformed ward that fell at very weakly applied compliance index.

It is therefore, deduced that, the surveyed BRPs in both cities weakly complied with FAO technical requirements. This compliance that is interpreted as not satisfactory is caused by existence of more stringent provisions in food technical requirements than actual conditions in the field of beef quality management. The implication is that we failed to reject the null hypothesis which hypothesizes that the visited beef retailing points do not comply with the technical requirements. The levels of compliance observed from test of hypotheses were lower than that observed in other researches on compliance in other parts of the developed world. This is in line with other studies in their findings that indicate poor handling during which carcasses, quarters, unwashed offal, and other items placed together on the floor or dirty concrete or wooden tables in retailing shops, increasing the microbial contamination of the meat.

The study finally identified the local infrastructural beef quality determinants in LDCs' BRPs as the gap to be bridged by other studies.

\section{Conflicts of Interest}

The authors declare no conflicts of interest regarding the publication of this paper. 


\section{References}

[1] Berezina, L., Samoilyk, I. and Sosnovska, O. (2016) Problems and Prospects of Logistics in Market. Zeszyty Naukowe Politechniki Częstochowskiej, 21, 26-35. https://doi.org/10.17512/znpcz.2016.1.03

[2] Tatum, J.D., Belk, K.E., George, M.H. and Smith, G.C. (1999) Identification of Quality Management Practices to Reduce the Incidence of Retail Beef Tenderness Problems: Development and Evaluation of a Prototype Quality. Journal of Animal Science, 77, 2112-2118. https://doi.org/10.2527/1999.7782112x

[3] Polkinghorne, R.J. and Thompson, J.M. (2010) Meat Standards and Grading: A World Review. Meat Science, 86, 227-235. https://doi.org/10.1016/j.meatsci.2010.05.010

[4] Adzitey, F., Teye, G.A. and Dinko, M.M. (2011) Pre and Post-Slaughter Animal Handling by Butchers in the Bawku Municipality of the Upper East Region of Ghana. Pakistan Veterinary Journal, 39, 177-184.

[5] Chepkemoi, S., Lamuka, P.O., Abong, G.O. and Matofari, J. (2015) Sanitation and Hygiene Meat Handling Practicesin Small and Medium Enterprises Butcheries in Kenya: Case Study of Nairobi and Isiolo Counties. Internet Journal of Food Safety, 15, 64-74.

[6] Mwashiuya, J.T., Manyele, S.V. and Mwaluko, G. (2018) Assessment of Beef Transportation Infrastructure from Slaughtering Facilities in Tanzanian Cities. Engineering, 10, 814-836. https://doi.org/10.4236/eng.2018.1011057

[7] Tonsor, G.T., Mintert, J.R. and Schroeder, T.C. (2010) U.S. Meat Demand: Households Dynamics and Media Information Impacts. Journal of Agricultural and Resource Economics, 35, 1-17.

[8] Fearne, A., Hornibrook, S. and Dedman, S. (2001) Management of Perceived Risk in the Food Supply Chain: A comparative Study of Retailer-Led Beef Quality Assurance in Schemes in Germany and Italy. International Food and Agribusiness Management Review, 4, 19-36. https://doi.org/10.1016/S1096-7508(01)00068-4

[9] Trent, N., Ormel, P., de Siles, J.L.G., Heinz, G. and James, M. (2003) The State of Meat Production in Developing Countries: 2002. In: Salem, D.J. and Rowan, A.N., Eds., The State of Animals II, Humane Society Press, Washington DC, 175-191.

[10] Ntanga, P.D., Mdegela R.H. and Nonga, H.E. (2014) Assessment of Beef Microbial Contamination at Abattoir and Retail Meat Shops in Morogoro Municipality, Tanzania. Tanzania Veterinary Journal, 29, 53-61.

[11] Ashenafi, M. (1994) Microbial Flora and Incidence of Some Food-Borne Pathogens on Fresh Raw Beef from Butcher's Shops in Awassa, Ethiopia. Bulletin of Animal Health and Production in Africa.

[12] Ali, N.H., Farooqui, A. Khan, A., Khan, A.Y. and Kazmi, S.U. (2010) Microbial Contamination of Raw Meat and Its Environment in Retail Shops in Karachi, Pakistan. The Journal of Infections in Developing Countries, 4, 382-388. https://doi.org/10.3855/jidc.599

[13] Clemen, R.T. and Winkler, R.L. (1999) Combining Probability Distribution from Experts in Risk Analysis. Risk Analysis, 19, 187-203. https://doi.org/10.1111/j.1539-6924.1999.tb00399.x

[14] Edget, A., Shiferaw, D. and Mengistu, S. (2010) Microbial Safety and Its Public Health Concern of E. coli O157:H7 and Salmonella spp. in Beef at Dire Dawa Administrative City and Haramaya University, Ethiopia. Journal of Veteronary Medicine and Animal Health, 9, 213-227. 
[15] Lulietto, M.F., Sechi, P., Borgogni, E. and Cenci-Goga, B.T. (2016) Meat Spoilage: A Critical Review of a Neglected Alteration Due to Ropy Slime Producing Bacteria. Italian Journal of Animal Science, 14, 316-326. https://doi.org/10.4081/ijas.2015.4011

[16] Adzitey, F. and Huda, N. (2012) Effect of Post-Slaughter Carcass Handling on Meat Quality. Pakistan Veterinary Journal, 32, 161-164.

[17] Mengistu, S., Abayneh, E. and Shiferaw, D. (2018) E. coli 0157: H7 and Samonella Species: Public Health Importance and Microbial Safety in Beef at Selected Slaughter Houses and Retail Shops in Eastern Ethiopia. Journal of Veterinary Science and Technology, 8, 468. https://doi.org/10.4172/2157-7579.1000468

[18] Tebbutt, G., Bell, V. and Aislabie, J. (2006) Verification of Cleaning Efficiency and its Possible Role in Programmed Hygiene Inspections of Food Businesses Undertaken by Local Authority Officers. Journal of Applied Microbiology, 102, 1010-1017. https://doi.org/10.1111/j.1365-2672.2006.03151.x

[19] FAO (2015) The Red Meat Value Chain in Tanzania. A Report from the Southern Highlands Food Systems Programme.

[20] Kamugisha, P.P., Mdoe, N.S.Y. and Mtenga, L.A. (2017) Characterizing the Tanzanian Quality Beef Supply Chain: A Case of Arusha and Dar es Salaam cities. Livestock Research for Rural Development, 29.

[21] Khonje, M.G. and Qaim, M. (2019) Modernization of African Food Retailing and (Un) Health Food Consumption. Sustainability, 11, 4306. https://doi.org/10.3390/su11164306

[22] Muzzo, B.I. and Provenza, F.D. (2018) A Review of Strategies for Overcoming Challenges of Beef Production in Tanzana. Livestock Research for Rural Development, 30, 12.

[23] Greenwood, P.L., Gardner, G.E. and Ferguson, D.M. (2018) Current Situation and Future Prospects for the Australian Beef Industry-A Review. Asians-Australas Journal of Animal Science, 31, 992-1006. https://doi.org/10.5713/ajas.18.0090

[24] Kirsten, J.F., Vermeulen, H., van Zyl, K., du Rand, G., du Plessis, H. and Weissnar, T. (2017) Do South African Consumers Have an Appetite for an Origin-Based Certification System for Meat Products? A Synthesis of Studies on Perceptions, Preferences and Experiments. International Journal on Food System Dynamics, 8, 54-71.

[25] Irshad, F.I., Jackob, J.H. and Alhawamdeh, I. (2018) The Slaughtering and Dressing Procedures of Livestock Inside the Butcher Shops Generate High Levels of Bacterial Contamination. Journal of Basic \& Applied Science, 14, 165-173. https://doi.org/10.6000/1927-5129.2018.14.25

[26] Upadhayaya, M. and Ghimire, B. (2018) Survey on Good Hygiene Practices in Retail Meat Shops in Butwal Municipality, Nepal. Nepalese Veterinary Journal, 35, 110-121. https://doi.org/10.3126/nvj.v35i0.25248

[27] TFDA (2011) Guidelines for Registration and Licensing of Food Premises. Document No. TFDA/DFS/FI\&E/G/002, Revision 3.

[28] FAO (2014) Guideline of Hygiene and Safety in Food Retail Sector. RAP, Publication, 16.

[29] EAC (2001) Hygiene in the Food and Drink in the Manufacturing Industry-Code of Practice. East African Standard, 39.

[30] Winslow, R.L. (1982) Microbial of Meat-A Retailer's Approach. Journal of Food Protection, 45, 1169-1172. https://doi.org/10.4315/0362-028X-45.12.1169

[31] Garedew, L., Hagos, Z., Addis, Z., Tesfaye, R. and Zegeye, B. (2015) Prevalence and 
Antimicrobial Susceptibility Patterns of Salmonella Isolates in Association with Hygienic Status from Butcher Shops in Gondar Town, Ethiopia. Antimicrobial Resistance and Infection Control, 4, 21. https://doi.org/10.1186/s13756-015-0062-7

[32] Mirembe, B.B., Ndejjo, R. and Musoke, D. (2015) Sanitation and Hygienic Status of Butcheries in Kampala, Uganda. African Journal of Food Agriculture, 15, 1-8.

[33] Komba, E.V.G., Komba, E.V., Mkupasi, E.M., Mbyuzi, A.O., Mshamu, S., Luwumba, D., Busagwe, Z. and Mzula, A. (2012) Sanitary Practices and Occurrence of Zoonotic Conditions in Cattle at Slaughter Morogoro Municipality, Tanzania. Implication for Public Health. Tanzania Journal of Health Research, 14, 1-12. https://doi.org/10.4314/thrb.v14i2.6

[34] Hagen, J.M. (2002) Causes and Consequences of Food Retailing innovation in Developing Countries: Supermarkets in Vietnam. Working Paper No. 26.

[35] Todd, E.C.D., Greig, J.D., Bartleson, C.A. and Michaelis, B.S. (2009) Outbreaks Where Food Workers Have Been Implicated in the Spread of Foodborne Disease, Part 6. Transmission and Survival of Pathogens in the Food Processing and Preparation Environment. Journal of Food Protection, 72, 202-219. https://doi.org/10.4315/0362-028X-72.1.202

[36] Algabry, I.M.I., Ahmed, A.A., Ibrahim, H.A.A. and Samaha, I. (2012) Hygiene of Butcher Shop in Alexandria. Journal of Veterinary Science, 37, 23-31.

[37] Afolabi, F.T., Arowosebe, A.R. and Adeyemo, S.M. (2017) Investigation on Microbial Quality of Raw Meats Sold in Some part of Ibadan Metropolis, Nigeria, Annals. Food Science and Technology, 18, 512-520.

[38] Siyanbola, A.A., Zaharadeen, A. and Sdegboye, K. (2014) Assessment of Compliance with Disclosure Requirements of SAS 3 and IAS 16 by Listed Agricultural Firms in Nigeria. International Journal of Applied Research and Technology, 3, 117-129.

[39] Triola, M.M., Mario, M.D. and Triola, F. (2006) Biostatistics for Biological and Health Sciences. Pearson Education, Inc., San Francisco, CA.

[40] Mgimba, C. and Sanga, A. (2016) Municipal Solid Waste Composition Characterization for Sustainable Management Systems in Mbeya. International Journal of Science, Environment and Technology, 5, 47-58.

[41] Ndetto, E. and Matzarakis, A. (2013) Basic Analysis of Climate and Urban Bioclimate of Dar es Salaam, Tanzania. Theoretical Applied Climatology, 114, 213-226. https://doi.org/10.1007/s00704-012-0828-2 